\title{
Estratégia de Pesquisa sobre os Conhecimentos, Atitudes e Práticas Financeiras das Famílias Inscritas no Cadastro Único para Programas Sociais
}

\section{Introdução}

O Ministério do Desenvolvi-

ciários terão acesso a diversos mento Social e Combate à Fome (MDS) e a Caixa Econômica Federal (CEF), agente operador da folha de pagamento dos benefícios mensais do Programa Bolsa Família (PBF), lançaram, em outubro de $2009^{1}$, o Projeto de Inclusão Bancária dos Beneficiários do PBF. Por meio da iniciativa, os beneficiários têm sido encorajados a abrir contas bancárias simplificadas na CEF (Conta "Caixa Fácil"). Além de poder receber o benefício mensal do programa sob a forma de créditos transferidos para as contas, os benefiserviços e produtos financeiros, com os quais a maioria não está habituada a lidar.

A fim de promover o uso responsável dos serviços e produtos disponibilizados por meio da abertura das contas, o MDS pretende implementar, em âmbito nacional, uma série de ações de educação financeira voltadas para as famílias de baixa renda - assim consideradas as famílias que atendem aos requisitos para inclusão no Cadastro Único para Programas Sociais (Cadúnico) ${ }^{2}$. 
Desde que incorporou esta agenda, o MDS tem buscado o apoio de parceiros com experiência nos campos da educação e inserção financeira, dentro e fora do governo, no país e no exterior, que possam auxiliá-lo a conceber e a executar tais ações. A primeira iniciativa do ministério nesse sentido foi se aproximar do grupo encarregado da proposição da Estratégia Nacional de Educação Financeira (ENEF)3, que reúne representantes do sistema financeiro nacional, de diversos ministérios e da sociedade civil.

O contato com esses e outros atores, somado ao levantamento da literatura sobre inserção e educação financeira, levou os gestores do MDS a constatar a escassez de estudos com foco em públicos semelhantes - quanto ao nível de renda, escolaridade, entre outros aspectos - aos beneficiários do PBF e demais inscritos no Cadúnico. Para suprir tal lacuna, a Secretaria de Avaliação e Gestão da Informação (SAGI) e a Secretaria Nacional de Renda de Cidadania (SENARC) decidiram levantar dados primários e informações que possam servir de subsídios ao desenvolvimento das ações de educação financeira para as famílias de baixa renda. 0 presente relato apresenta a estratégia de investigação proposta pelas duas secretarias e informa seu estágio atual de desenvolvimento.

1 A data corresponde ao lançamento oficial do Projeto de Inclusão Bancária, que já estava, contudo, sendo implementado, em estágio "piloto", desde março de 2008, na cidade de Belo Horizonte.

2 Nesta base de dados são registradas famílias com renda mensal de até meio salário mínimo per capita ou três salários mínimos no total. Famílias com renda superior aos limites mencionados podem ser inseridas na base, desde que sua inclusão esteja vinculada à seleção ou ao acompanhamento de programas e serviços socioassistenciais.

3 A ENEF foi instituída pelo Decreto n 7.397, de 22 de dezembro de 2010.

Revista Brasileira de Monitoramento e Avaliação | Número 1 | Janeiro-Junho de 2011 


\section{Relato de caso}

A estratégia de pesquisa definida pela SAGI e pela SENARC compreende quatro etapas articuladas e sucessivas, porém metodologicamente distintas:

- realização de cinco grupos focais com pessoas inscritas no Cadúnico, visando uma primeira aproximação com o tema, bem como a obtenção de subsídios para elaboração de um questionário para pesquisa nacional sobre os conhecimentos, atitudes e práticas das famílias inscritas no Cadúnico em relação às suas finanças, aos seus orçamentos familiares e ao seu relacionamento com o sistema financeiro formal e informal;

- análise dos resultados dos grupos focais para definição dos blocos temáticos explorados na pesquisa nacional e delineamento de questões. O questionário decorrente dessa análise foi estruturado nos seguintes blocos: composição e administração do orçamento familiar; planejamento e decisões financeiras; acesso ao sistema financeiro e uso de serviços e produtos; percepções e interesses relativos a ações de educação financeira;

- aplicação do questionário na pesquisa nacional, que compreende entrevistas em 8.807 domicílios de famílias inscritas no Cadúnico, distribuídas entre 265 municípios. Estão sendo entrevistados o responsável familiar identificado no Cadúnico bem como seu cônjuge, caso este resida no mesmo domicílio. Espera-se com isso explorar a dinâmica intrafamiliar associada às decisões financeiras domésticas;

- análise dos dados coletados na pesquisa nacional com vistas à proposição de ações de educação financeira para as famílias de baixa renda.

As duas primeiras etapas da estratégia já foram concluídas. Os grupos focais mencionados foram realizados em cinco municípios, distribuídos nas cinco grandes regiões do país: Campinas (SP); Pinhais (PR); Catalão (GO); Curuçá (PA) e Alto do Rodrigues (RN). A seleção dessa amostra 
intencional considerou o porte populacional dos municípios, sua dinâmica econômica e a facilidade de acesso a eles. Nos casos dos municípios de menor porte, evitou-se ainda a inclusão daqueles que estivessem conurbados a um centro metropolitano, uma vez que nesses casos a população dos municípios de pequeno porte pode ter acesso facilitado a bens e serviços financeiros. De maneira geral, observou-se nos grupos que:

- a inadimplência decorre muito mais da precariedade e insuficiência de renda que do descontrole financeiro das famílias;

- o nível de aspiração de consumo é baixo, dificultando o endividamento excessivo;

- o recurso pago pelo Programa Bolsa Família é percebido como um importante colateral positivo - a regularidade do pagamento possibilita às famílias o planejamento de seus gastos e a utilização de seus recursos em compras parceladas;
- os participantes têm receio de abrir conta bancária e desconhecem suas funcionalidades;

- os correspondentes bancários são, em geral, mais acessados do que os bancos, pela facilidade de acesso (proximidade do local onde moram) e pela simplicidade das operações financeiras (diretamente no caixa).

Conforme descrito acima, os resultados dos grupos focais, dos quais os exemplos citados são apenas uma pequena parcela, fundamentaram a elaboração do questionário aplicado na pesquisa nacional. A coleta dos dados dessa pesquisa encontra-se em curso, com previsão de término em junho próximo, quando então as bases de dados estarão prontas para uma análise consolidada. A partir dessa análise, serão propostas ações de educação financeira para a população de baixa renda. Em seu conjunto, trata-se de uma estratégia de investigação inédita no país, considerando-se o público, os temas por ela abordados e o fim a que se destina. 